\title{
Evaluation of Transverse Strength of Heat Cure Denture Bases Repaired with Different Joint Surface Contours: An In Vitro Study
}

\author{
Nallamilli Mamatha ${ }^{1}$, Praveen K Madineni ${ }^{2}$, Rapolu Sisir ${ }^{3}$, Siripurapu Sravani ${ }^{4}$, Saimadhavi Nallamilli ${ }^{5}$, Jorige R Jyothy ${ }^{6}$
}

\begin{abstract}
Aim: The present in vitro study aimed to evaluate the transverse strength of heat cure acrylic denture base resins repaired with three different joint surface designs, repair material being the glass-fiber-reinforced self-cure repair material along with surface pretreatment.

Materials and methods: A total of 40 heat cure resin specimens were fabricated and finished to a size of $64 \mathrm{~mm} \times 10 \mathrm{~mm} \times 2.5 \mathrm{~mm}$. These specimens were divided into four groups of 10 each, with butt, round, and bevel repair surface joints, respectively, along with the control group. After the specimens were cut in the middle for the repair procedure to proceed, the aforementioned joint surface contours were prepared for groups II II, and III, respectively, treated with dimethyl chloride for 30 seconds, and the repair was done with E-glass-fiber-reinforced self-cure repair material.

Results: The mean transverse strength of the control group was $100.37 \mathrm{~N}$, which was highest (significant $p$ value of $<0.05$ ), followed by group III (bevel joint) $54.23 \mathrm{~N}$, group I (butt joint) $53.93 \mathrm{~N}$, and group II (round joint) $44.55 \mathrm{~N}$.

Conclusion: Distribution of stresses evenly in the repair region will be achieved by the proper selection of the joint surface contour, and this study showed that the $45^{\circ}$ bevel joint was an appropriate selection along with promising repair material and surface pretreatment.

Clinical significance: Clinically, in the event of repairing a broken denture, a rapid and economically convenient material with superior physical and mechanical properties is important to maintain the adequate transverse strength of the repaired denture. Glass-fiber-reinforced autopolymerizing resin, with a $45^{\circ}$ bevel joint design of the broken surfaces and surface pretreatment proved to reduce stress concentration, improving the transverse strength of the repaired heat cure denture base resins.

Keywords: Autopolymerizing repair material, Denture repair, Fiber glass reinforcement, Joint surface design, Surface pretreatment.

The Journal of Contemporary Dental Practice (2020): 10.5005/jp-journals-10024-2758
\end{abstract}

\section{INTRODUCTION}

A clinician's first choice of approach in an event of broken denture would be repair of the existing denture, than opting for a new prosthesis, as the patient would be habituated with function and comfort an old prosthesis delivers. The prevalence of fractured dentures is not uncommon, and when a patient arrives with a broken denture to a clinician, owing to the patient's attitude, the first choice of approach would be repair of the existing denture, provided the occlusal vertical dimension should be satisfactory, the patient's appearance must be acceptable to the patient and dentist, the size, shape, shade, and arrangement of the artificial teeth must be satisfactory, and the oral tissue should be in optimum health. The denture base extensions, interocclusal distance and speech must be satisfactory with the existing teeth arrangement. ${ }^{1}$

If the aforementioned considerations have been met, then repairing the denture is the next commencing step. Various investigations had been carried out by many researchers concerning the repair material, surface design, chemical treatment, and any reinforcements in the repair material during the procedure in an effort to maintain adequate transverse strength and retain the dimensional accuracy of the repaired denture. ${ }^{2}$

Although autopolymerizing resin repairs are convenient to patients in view of time and affordability, unfortunately, the repaired units had been proved to lose $40 \%-60 \%$ of their original transverse strength. Additional methods such as integration of different fibers with varied architectures and surface pretreatments were
${ }^{1-4}$ Department of Prosthodontics, MNR Dental College and Hospital, Hyderabad, Telangana, India

${ }^{5}$ Department of Oral Medicine and Radiology, Drs Sudha and Nageswara Rao Siddhartha Institute of Dental Sciences, Gannavaram, Vijayawada, Andhra Pradesh, India

${ }^{6}$ Department of Prosthodontics, Government Dental College and Hospital, Hyderabad, Telangana, India

Corresponding Author: Nallamilli Mamatha, Department of Prosthodontics,MNRDentalCollegeandHospital,Hyderabad,Telangana, India, Phone: +91 9949976749, e-mail: mamathamuralidhar160@ gmail.com

How to cite this article: Mamatha N, Madineni PK, Sisir R, et al. Evaluation of Transverse Strength of Heat Cure Denture Bases Repaired with Different Joint Surface Contours: An In Vitro Study. J Contemp Dent Pract 2020;21(2):166-170.

Source of support: Nil

Conflict of interest: None

suggested to enhance the physical and mechanical properties of acrylic dentures. Among the factors that contribute to the strength of repair, the type of joint used is of paramount importance. Different designs such as primarily smooth and rough interface surfaces, joints with mechanical retention, butt joint, $45^{\circ}$ bevel joints, and rounded and rabbeted joints have been explored with varying results. As the prevalence of fractured dentures is not 
uncommon, more literature is warranted in this area to establish a desirable repair procedure. ${ }^{3}$

In this regard, the present in vitro study aimed to evaluate the transverse strength of heat cure acrylic denture base resins repaired with three different joint surface designs, repair material being the glass-fiber-reinforced self-cure repair material along with surface pretreatment. Null hypothesis states that difference exists in the effect of different joint surface contours on the transverse strength of repaired heat cure acrylic resins.

\section{Materials and Methods}

The standardized steel dies measuring $65 \mathrm{~mm} \times 10 \mathrm{~mm} \times 3 \mathrm{~mm}$ were prepared according to American Dental Association specification no. 12 and were invested using type III gypsum product (Fig. 1). The mold spaces were used as matrices for the fabrication of heat polymerized acrylic resin specimens. A total of 40 heat cure resin specimens were fabricated as per the manufacturer's instructions, finished to a size of $64 \mathrm{~mm} \times 10 \mathrm{~mm} \times 2.5 \mathrm{~mm}$ with silicon carbide paper under water irrigation. The specimens were categorized into four groups of 10 each: group I-with butt, group II-round, and group III-bevel repair surface joints, respectively, along with

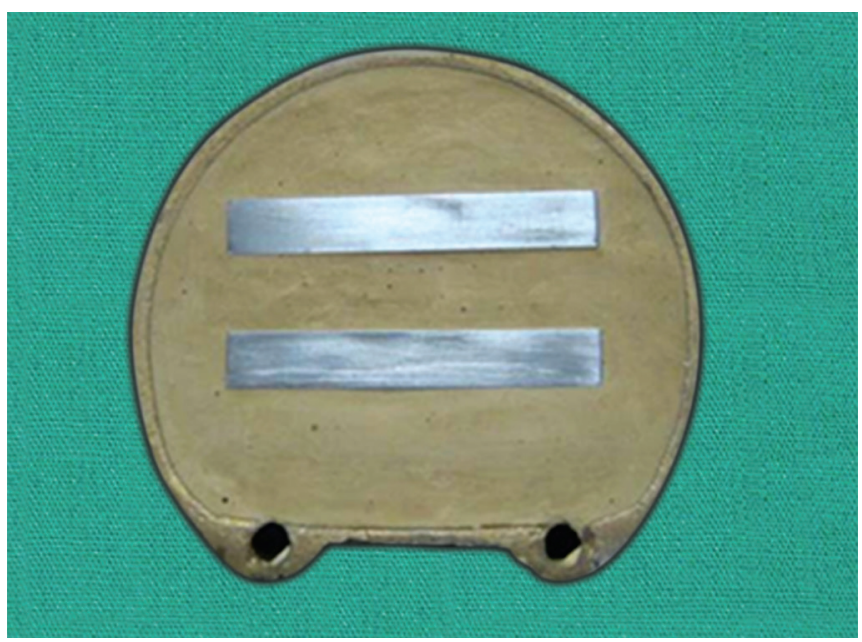

Fig. 1: Stainless steel dies invested in type III gypsum product

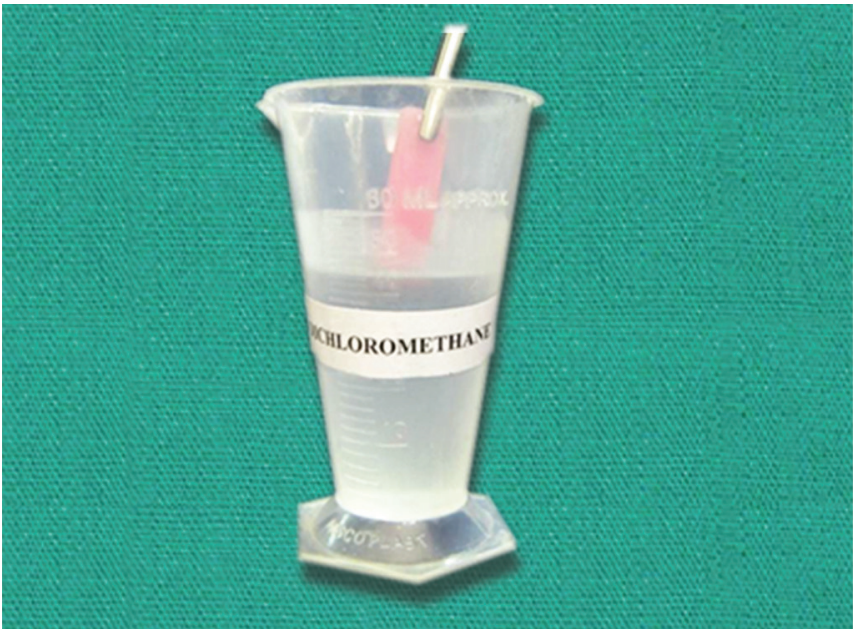

Fig. 3: Surface pretreatment using dimethyl chloride before the repair procedure was started the control group, that is, group IV that was unrepaired heat cure acrylic resin specimens (Fig. 2).

A central recess channel of $30 \mathrm{~mm} \times 5 \mathrm{~mm} \times 1 \mathrm{~mm}$ was prepared in the specimens to reinforce the E-glass fibers during the repairing procedure. Then, the specimens were cut in the middle, and different joint surface contours were prepared accordingly. The specimen ends that are to be repaired were soaked in the methylene chloride for 30 seconds (Fig. 3), and it should be mentioned that the stone index was used as a repair index. Repairing procedure starts with positioning the specimen in the repair index and reinforcing material, that is, E-glass fiber placed in the central recess channel (Fig. 4). An autopolymerizing acrylic resin was filled into the spaces with sprinkle on technique, and the material was slightly overfilled to compensate for polymerization shrinkage and finishing. Specimens of all the groups were repaired with the same procedure, and after polymerization, all the specimens were trimmed and finished to their original dimensions. Before commencing for the test, they were stored in water for 48 hours (Fig. 5).

A three-point bending test was performed with a Universal testing machine, at a crosshead speed of $5 \mathrm{~mm} /$ minute at a $50-\mathrm{mm}$

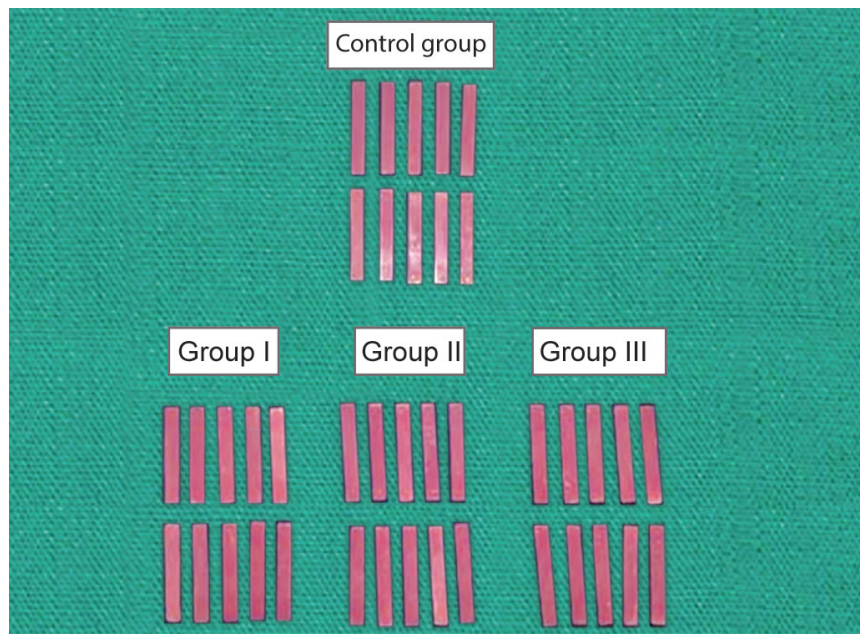

Fig. 2: Fabrication of all heat cure acrylic resin specimens

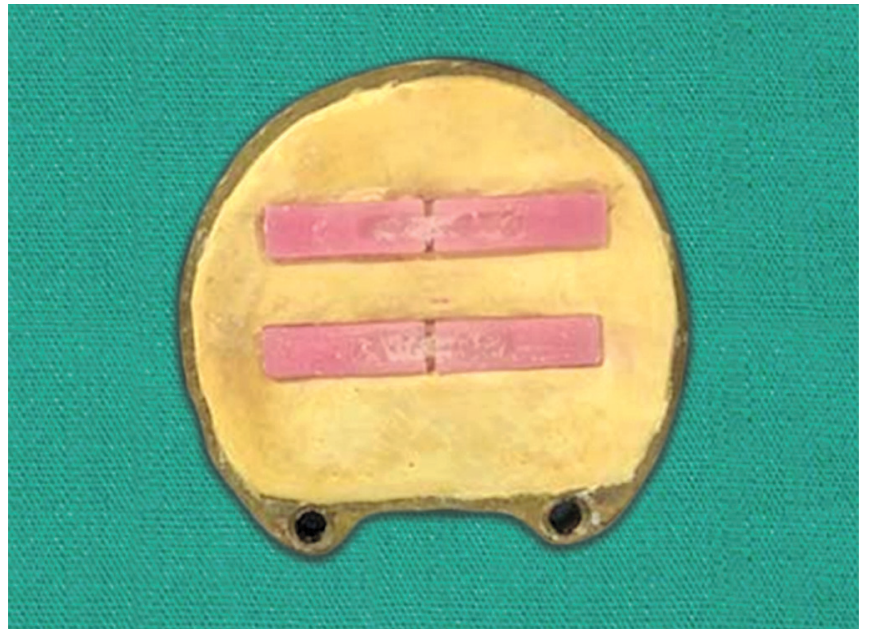

Fig. 4: E-glass fiber mesh was reinforced in self-cure acrylic repair material 


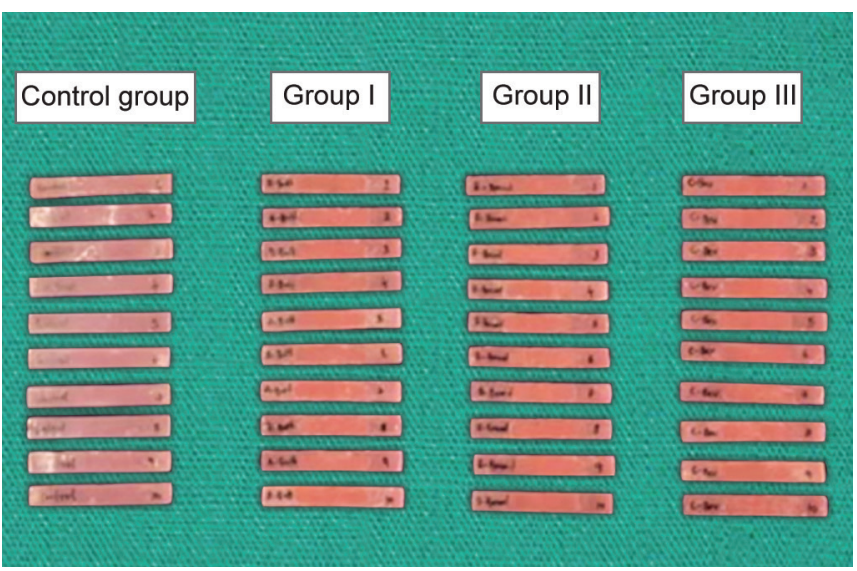

Fig. 5: All the specimens after the repair procedure was finished

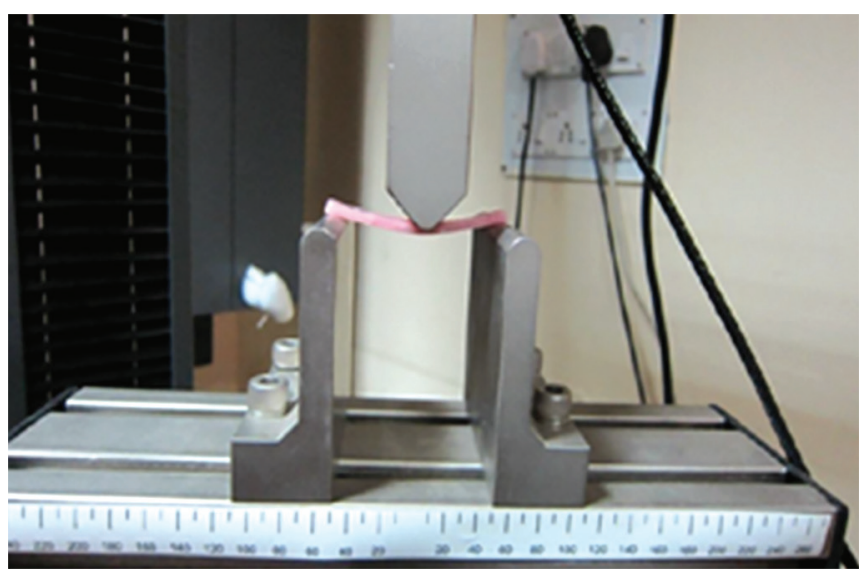

Fig. 6: Acrylic resin specimen loaded on universal testing machine and subjected to fracture load

Table 1: Mean transverse strength of repaired specimens of all the groups

\begin{tabular}{|c|c|c|c|c|c|c|c|c|c|c|}
\hline & \multicolumn{2}{|c|}{ Group I } & \multicolumn{2}{|c|}{ Group II } & \multicolumn{2}{|c|}{ Group III } & \multicolumn{2}{|c|}{$\begin{array}{l}\text { Control group/ } \\
\text { group IV }\end{array}$} & \multirow[b]{2}{*}{$p$ value } & \multirow[b]{2}{*}{ Post hoc test } \\
\hline & Mean & $S D$ & Mean & $S D$ & Mean & $S D$ & Mean & $S D$ & & \\
\hline $\begin{array}{l}\text { Transverse } \\
\text { strength }\end{array}$ & 53.93 & 13.91 & 44.55 & 13.82 & 54.23 & 15.33 & 100.37 & 16.23 & $<0.001 ;$ Sig. & $\begin{array}{l}\text { Control group/ } \\
\text { groups IV > I, II, and III }\end{array}$ \\
\hline
\end{tabular}

SD, standard deviation

Table 2: Intergroup comparisons

\begin{tabular}{ll}
\hline Intergroup & $p$ value \\
\hline 1 vs 4 & $<0.001 ;$ Sig. \\
2 vs 4 & $<0.001 ;$ Sig. \\
3 vs 4 & $<0.001$; Sig. \\
\hline
\end{tabular}

distance (Fig. 6). The load applied to the center of the specimens was measured by a load cell, attached to the crosshead of the machine via a data acquisition system connected to a computer. The breaking load was noted in Newton, and the procedure was repeated accordingly for all the specimens. These breaking load values were converted to transverse repair strength values $(S)$ by the formula $S=3 P L / 2 b d_{1}{ }^{2}$ where $S$ is the transverse strength of the specimen in mega pascal, $P$ is the load at fracture, $L$ is the length between the jig tips (50 mm), $b$ is the width $(10 \mathrm{~mm})$, and $d$ is the thickness of the specimen $(3 \mathrm{~mm})$. Comparison of mean transverse strength among the four study groups was done using analysis of variance (ANOVA) with post hoc Dunnett's test.

\section{Results}

All the analysis was done using SPSS version 18, and the results showed a $p$ value of $<0.05$ as statistically significant. Comparison of mean transverse strength among the four study groups was done using ANOVA with post hoc Dunnett's test (Table 1). The mean transverse strength of the control group, that is, group IV was 100.37 $\mathrm{N}$, which was highest among other groups and signifies the general fact that heat cure acrylic resin exhibits highest transverse strength. In the intergroup comparison (Table 2), the mean transverse strength of group III (bevel joint) $54.23 \mathrm{~N}$ was higher followed by group I (butt joint) $53.93 \mathrm{~N}$ and group II (round joint) $44.55 \mathrm{~N}$.

\section{Discussion}

One of the important parameters to be considered while repairing the broken denture base is the selection of an appropriate material which depends on the working time and the strength to be obtained with the repair material. Although literature reveals that various materials such as autopolymerizing acrylic resin, heatpolymerized acrylic resin, visible light-polymerized resin, and microwave polymerized acrylic resin are being used since ages, selection of an appropriate one seems to be challenging. ${ }^{2,3}$

In this study, self-cure was used as a repair material for its quick and easy procedural steps and availability. However, owing to its inadequate transverse strength, various methods were suggested for enhancing the overall repair strength. Keyf and Uzun observed that reinforcing the self-cure with glass fiber has notably increased its resistance to crack propagation and the modulus of elasticity, that is, stiffness in the repaired denture base resin specimens, ${ }^{4}$ and the finding was also supported by Vallittu ${ }^{5}$ and Vasthare, Shetty. ${ }^{6}$ In this study, E-glass fibers (ADVANTEX ${ }^{\mathrm{TM}}$ Glass Fiber; Owens Corning India Ltd, Lot No. 06148T304; diameter: $16.8 \mu \mathrm{m}$ ) were reinforced in a mesh form by preparation of central recess channel in the heat cure specimens.

In addition to this, it has been in the literature that the adhesion of denture base and repair material can also be enhanced by applying appropriate chemicals, that is, surface pretreatment to the acrylic resin surfaces. ${ }^{7}$ The surface pretreatment used in this study was in agreement with the study by Nagai et al., ${ }^{8}$ in which the application of methylene chloride for 30 seconds to heat cure surfaces enhanced the transverse strength by $12 \%$ when repaired with autopolymerizing acrylic resin.

The weakest point of the repaired denture bases is the interface between the heat-polymerized acrylic resin and the repair material. 


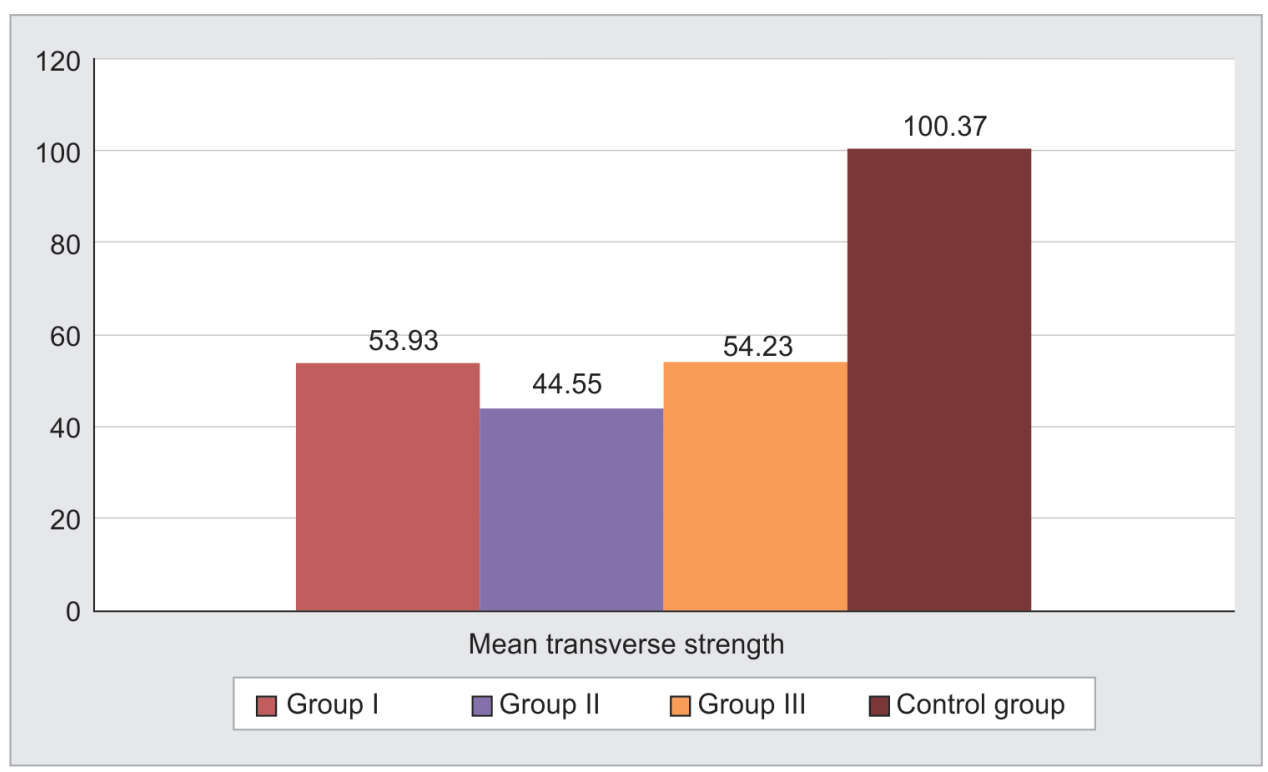

Fig. 7: Graphical representation showing the mean transverse strength of all groups

To overcome this drawback, many attempts were made to improve the bond strength by mechanical surface modification. Several studies have indicated different edge profiles, such as a butt joint, 3,9 $45^{\circ}$ bevel joint, ${ }^{3,5} 30^{\circ}$ bevel joint, $55^{\circ}$ bevel joint, rounded, ${ }^{2,9-11}$ and rabbet joint, but the present study used butt, round, and $45^{\circ}$ bevel joints as the repair joint contours due to their prevalence of use in dental clinics.

Results of the present study showed that the control group exhibited highest transverse strength among all the groups even though the reinforcements and pretreatment was done in the study groups. Control group was followed by bevel, butt, and round joint groups in decreasing transverse strengths, respectively, which was similar to the study done by Sharma and Batra ${ }^{12}$ and contradictory to the study done by Anasane. ${ }^{13}$ It could be taken that the greater transverse strength of bevel joint might be due to greater surface area of contact between repair and base material eventually resulting in stress distribution. With both butt and round joints, there were sharp angled surfaces that promote stress concentration, which will be directly related to the degree and abruptness of surface change.

As shown in Figure 7, slightly significant difference was found between the butt (53.93 MPa) and bevel joint (54.23 MPa), but greater difference was found between bevel and round, butt and round with the round being inferior ( $44.55 \mathrm{MPa})$. Greater difference between butt and round joints is conflicting with the previous studies, ${ }^{10,14}$ which reported that the rounded and beveled joints were superior compared with that of butt joint. This disparity might be attributed to the fact that the rounded design prepared in this study was different from the design prepared in the aforementioned studies.

The round joint contour prepared in this study was in accordance with Mahajan et al., in which they concluded that rounded joint design was superior. ${ }^{15}$ But the results of this study were not in accordance with the aforementioned author and clear disparity was seen. This variation might be because of the same reason as with the butt joint, where the sharp-angled surface was more prominent with round joint as only the joint contour is of round design but the sharp angles were present like butt joint that promotes stress concentration.
Therefore, when repairing fractured acrylic resin prosthesis, one should attempt to limit residual stress, by adapting a $45^{\circ}$ bevel joint that shifts the interfacial stress pattern more toward a shear stress and away from the more damaging tensile stress, to prevent recurrent structural fracture by distributing these stresses as evenly as possible. $^{13}$

Going by various studies done to improve the repaired dentures strength, a recent study done by Mohammed Gad showed that zirconia $\left(\mathrm{ZrO}_{2}\right)$, a metal oxide, could be used as a reinforcement material to enhance the transverse strength of denture base resin. More recently, prosthodontic field was invaded by nanotechnology for medical and material enhancement purposes. The size, shape, type, and concentration of the added nanoparticles will decide the ultimate desirable property of the reinforced resin. The small size and hemogeneous distribution of nanozirconia to polymethylmethacrylate seem to increase the transverse strength of denture base, thus making it an ideal material in the near future. ${ }^{16}$ More studies are needed to evaluate and confirm the efficacy of the aforementioned materials as the reinforcements in repairing procedures.

\section{Conclusion}

In conclusion, the control group exhibited highest transverse strength followed by the $45^{\circ}$ bevel joint design specimens repaired with dimethyl chloride surface pretreatment and E-glass-fiberreinforced self-cure repair material. Apart from joint surface contours which have a significant role in the success of repaired dentures, various studies on reinforcements have evolved recently such as silica nanoparticles and zirconia nanoparticles, ${ }^{15}$ which are being investigated, are proven to have more significant transverse strength than conventional methods.

\section{Clinical Significance}

Clinically, in the event of repairing a broken denture, a rapid and economically convenient material with superior physical and mechanical properties is important to maintain the adequate transverse strength of the repaired denture. Glass-fiber-reinforced 
autopolymerizing resin, with a $45^{\circ}$ bevel joint design of the broken surfaces and surface pretreatment, proved to reduce stress concentration, improving the transverse strength of the repaired heat cure denture base resins.

\section{References}

1. Winkler S. Essentials of Complete Denture Prosthodontics, 3rd ed., MDMI, Inc: Sheldon Winkler; 2002. p. 352

2. Shimizu H, Kurtz KS, Yoshinaga M. Effect of surface preparation on the repair strength of denture base resin. Int China J Dent 2002; 126-133.

3. Seó RS, Neppelenbroek KH, Filho JN. Factors affecting the strength of denture repairs. J Prosthodont 2007;16(4):302-310. DOI: 10.1111/j.1532-849X.2007.00191.x.

4. Stipho HD. Repair of acrylic resin denture base reinforced with glass fiber. J Prosthet Dent 1998;80(5):546-550. DOI: 10.1016/S00223913(98)70030-7.

5. Vallittu PK. Glass fiber reinforcement in repaired acrylic resin removable dentures: preliminary results of a clinical study. Quintessence Int 1997;28(1):39-44.

6. Vasthare A, Shetty S. Effect of different edge Profile, surface treatment, and glass fiber reinforcement on the transverse strength of denture base resin repaired with autopolymerizing acrylic resin: An in vitro study. J Interdiscip Dent 2017;7(1):31-37. DOI: 10.4103/jid. jid_80_16.

7. Shen C, Colaizzi FA, Birns B. Strength of denture repairs as influenced by surface treatment. J Prosthet Dent 1984;52(6):844-848. DOI: 10.1016/S0022-3913(84)80016-5.

8. Nagai E, Otani K, Satoh Y. Repair of denture base resin using woven metal and glass fiber: effect of methylene chloride pretreatment.
J Prosthet Dent 2001;85(5):496-500. DOI: 10.1067/mpr.2001. 115183.

9. Harrison WM, Stansbury BE. The effect of joint surface contours on the transverse strength of repaired acrylic resin. J Prosthet Dent 1970;23(4):464-472. DOI: 10.1016/0022-3913(70)90014-4.

10. Stipho HD, Stipho AS. Effectiveness and durability of repaired acrylic resin joints. J Prosthet Dent 1987;58(2):249-253. DOI: 10.1016/00223913(87)90186-7.

11. Lin C-T, Lee S-Y, Tsai TY, et al. Degradation of repaired denture base materials in simulated oral fluid. J Oral Rehabil 2000;27:190-198. DOI: 10.1046/j.1365-2842.2000.00513.x.

12. Sharma A, Batra P. Influence of repair material, surface design and chemical treatment on the transverse strength of repaired denture base - an in-vitro study. indian. J Dent Sci 2012;4(4):23-26.

13. Anasane $N$, Ahirrao $Y$, Chitnis $D$, et al. The effect of joint surface contours and glass fiber reinforcement on the transverse strength of repaired acrylic resin: An in vitro study. Dent Res J 2013;10(2):214-218. DOI: 10.4103/1735-3327.113347.

14. Hanna EA, Shah FK, Gebreel AA. Effect of joint surface contours on the transverse and impact strength of denture base resin repaired by various methods. An in vitro study. J Am Sci 2010;6(9):115-125.

15. Mahajan H, Chandu GS, Mishra SK. An in vitro study of the effect of design of repair surface on the transverse strength of repaired acrylic resin using autopolymerizing resin. Niger J Clin Pract 2014;17(1):38-42. DOI: $10.4103 / 1119-3077.122833$.

16. Nour el houda K. The use of silica nanoparticles and microwave irradiation with polymethyl methacrylate denture base resin: experimental investigation into the flexural strength and linear dimensional stability after repair and accelerated aging. Oral Health Care 2017;2(3):1-9. DOI: 10.15761/OHC.1000122. 